\title{
Smoothing Control Scheme of Photovoltaic Module through a Battery Energy Storage System
}

\author{
Bibekananda Jena, Sonali Goel, Renu Sharma
}

\begin{abstract}
The battery energy storage system (BESS) is basically used to smooth wind / solar power controlling. The constant current controller method is employed in order to eliminate the output fluctuation of Photovoltaic/ BESS power generation system. In this presented paper, the detailed description of the Grid associated PV structure along with battery and load is modeled and simulated in MATLAB / SIMULINK software.
\end{abstract}

Keywords: Solar Power, Current Controller, Fluctuation, Battery, Photovoltaic (PV)

\section{INTRODUCTION}

The world's electricity demand, including India, is increasing at an alarming rate, and electricity demand is ahead of supply. In the social sector of energy sector, agriculture, industry, transportation, business, or home consumes energy for day to day work. Energy has become dependent on fossil fuels with limited inventory of natural gas, oil and gas. Due to large amount of energy consumption, renewable sources for energy such as wind energy and solar energy plays key regarding energy generation. Global warming and serious air pollution is caused by excessive and continuous. Solar energy is naturally abundant and an inexhaustible source of energy. Solar energy can be used in two modes: stand-alone power generation units or grid-connected power generation units, which depends upon availability of nearby grids. Therefore, this can be utilized in order to supply power grid availability is lesser such as rural areas. Yet another benefit of solar power is elasticity to operate wheneverneeded.

To solve the current energy crisis, there exist long felt need for developing effective ways to extract power from solar radiation. With the development of materials science $\&$ power electronics, engineers are capable to endure high power demands by developing very small but powerful systems. However, "high power density" is a major problem with this type of system. However, due to their high production costs and low efficiency, these systems are rarely able to compete in the competitive market as a major power source. The consistent increase in solar cell manufacturing will ensure that these technologies may be utilized on a

Revised Manuscript Received on 14 August, 2019.

Bibekananda Jena, Department of Electrical Engineering, Institute of Technical Education and Research, Siksha 'O' Anusandhan(Deemed to be University), Bhubaneswar, Odisha, India.

SonaliGoel, Department of Electrical Engineering, Institute of Technical Education and Research, Siksha 'O' Anusandhan(Deemed to be University), Bhubaneswar, Odisha, India.(Email: sonali19881@gmail.com)

Renu Sharma, Department of Electrical Engineering, Institute of Technical Education and Research, Siksha 'O' Anusandhan(Deemed to be University), Bhubaneswar, Odisha, India. broader basis than the current scenario. The implementation of power control strategy known as "Maximum Power Point Tracker (MPPT)" is useful in the area of renewable energy sources as it is required to improve the operational solar modules implementation[1].

\section{MODELING OF PV ARRAY}

Photovoltaic (PV) array is basically a combination of multiple units interconnected in series/parallel combination to generate the necessary current and voltage. PV arrays are mathematically modeled by using MATLAB that utilizes solar cells equivalent circuit model. PV arrays are configured according to model requirements. As shown in figure1, a current input source is associated parallel and in series with diode in a simplified PV module structure, and PV array Simulink model as illustrated in Fig 2.

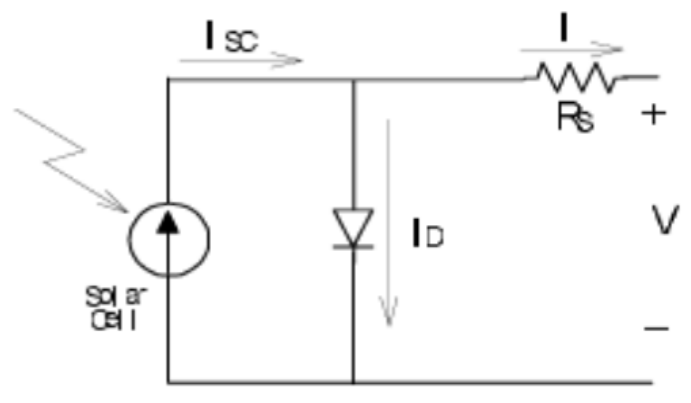

Fig.1 Equivalent model of a PV module

The operation of a PV array with an $\mathrm{N}_{S} \times \mathrm{N}_{P}$ unit may explained by the following formula. PV module parameters can be partially achieved through manufacturer's data sheet and may attained by some estimation methods [2].

$$
I_{P V}=N_{P} I_{S C}-N_{P} I_{0}\left(\exp \left(\frac{V_{a}+I_{a} R_{S}}{n N_{s} V_{t}}\right)-1\right)
$$

Where

$\mathrm{I}_{\mathrm{pv}}=\mathrm{PV}$ array output current $[\mathrm{A}]$

$\mathrm{I}_{\mathrm{sc}}=\mathrm{PV}$ module Short-circuit current $[\mathrm{A}]$

Io $=$ Saturation current of diode $[\mathrm{A}]$

$\mathrm{V}_{\mathrm{a}}=$ Terminal voltage of PV array [V]

$\mathrm{R}_{\mathrm{S}}=$ Series resistance $[\Omega]$

$\mathrm{n}=$ Constant of ideal diode

$\mathrm{V}_{\mathrm{t}}=\mathrm{PV}$ module's thermal potential [V]

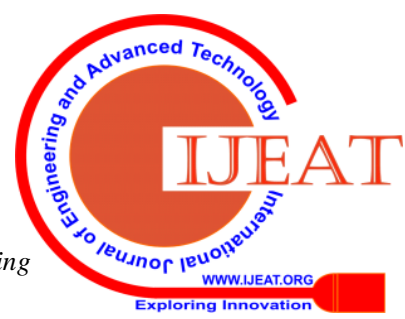




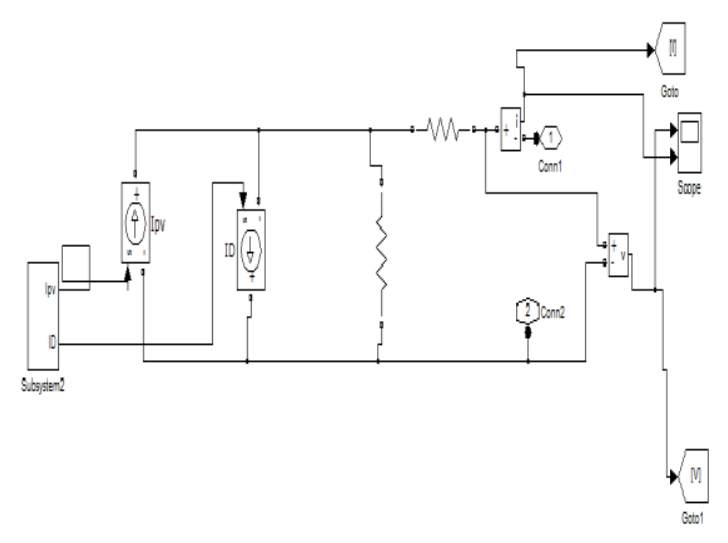

Fig.2 PV array MATLAB / Simulink model.

\section{MODELING OF BATTERY}

Grid associated structure batteries are intended for load supply and grids when no solar power is available. When the load is less, said battery gets charged from the array, generating extra power through said array, and if no power is supplied from the array, the load consumes whole energy of battery. In order to prevent the battery's depth of discharge, the charging state is monitored and whenever battery gets below $0 \%$, said battery gets disconnected from the load through breaker. The subsystem of battery designed in aMATLAB / simulationis as illustrated in Fig 3 .

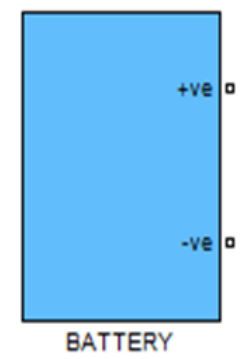

Fig.3 Subsystem of Battery in MATLAB/Simulink

\section{ON-GRID PHOTOVOLTAIC (PV)/ BATTERY SYSTEM}

PV array \& battery are interlinked with DC bus through a DC / DC converting unit associated with said grid through inverter. "Battery energy storage systems" helps in balancing power in between PV and load demand. When power generation exceeds demand, PV module charges said battery, and when power generation falls below demand, said load consumes battery energy. The circuit diagram of On-Grid hybrid PV / Battery system is shown in Figure 4.

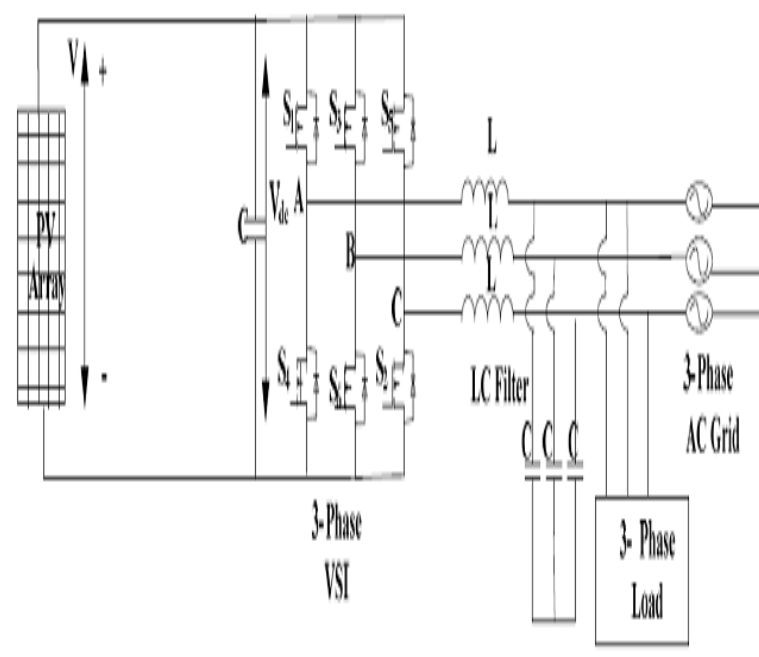

Fig.4 Outline of the On-Grid hybrid PV/Battery generation system

\subsection{Power Control at PV array side and MPPT}

PV module must work at some well-defined voltage that resembles to MPP as per operating conditions such as irradiance and temp. Therefore, for this purpose the MPPT technology is applied. Conventionally, Numerous MPPT technologies are proposed \& implemented, some of them are Lookup table method, "perturbation and observation (P \& O) method" and calculation method [2] [3] [4].

\subsection{Boost converteralong with its controller}

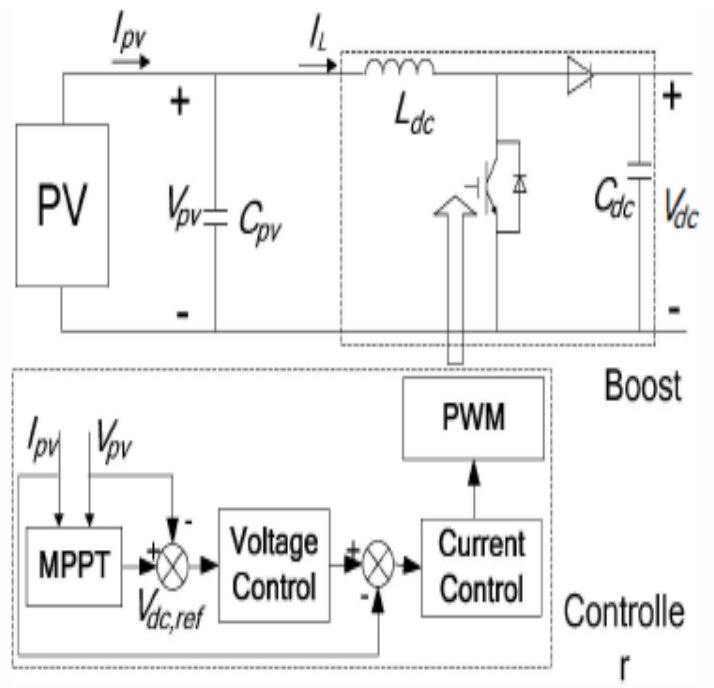

Fig.5 Boost converter and controller scheme

In a dual-phase PV generation, the chopper network is deployed as DC / DCconverter. Since the voltage coming out through PV module is less, by usage of boost converter circuit permits the use of a low-voltage PV array, thereby reducing the total price. Capacitor interconnected in between PV module and converter \& it is deployed in order to decrease harmonics. Fig 5 illustrates outline of boost converter network along with its control system.

Published By: Blue Eyes Intelligence Engineering 


\subsection{Battery energy storage system}

"Battery Energy Storage System (BESS)" comprises of a battery bank, bi-directionalDC / DC converting unit and controlling structure [5]. The system must capable of working with twoInstructions: one must charges said battery for storing excess energy and discharge the energy through the load. In the paper as illustrated in fig 6, the BESS is usually associated with DC bus using a bidirectional DC / DC converter.

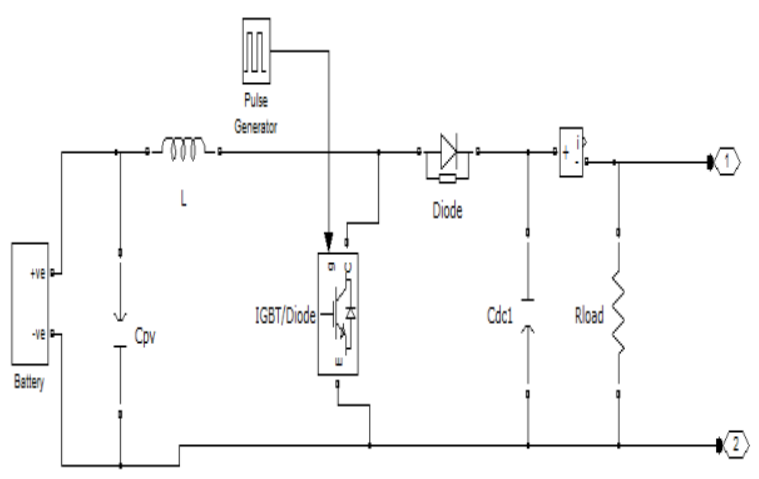

Fig.6 The bi-directional DC/DC converter
Grid considered as source of backup power, and battery provides short-term power in order to meet demand of load that the PV module cannot meet, especially during solar power fluctuations.

\subsection{Controlling scheme by grid-associated inverter}

PV module \& battery are interconnected with said grid through inverter. This inverter employed in SPWM constant current control method, the inductance current closely tracks the sinusoidal reference current command, and obtains the low THD injection current.

\section{SIMULATION RESULT}

According to model and controlling method, it's implementedin On-Grid PV generation in MATLAB / Simulink as illustrated in Fig 7. In this presented paper, the generated power of PV module is similar with said load demand and in case of the change in solar irradiancethe PV power generation is not similar with load demand \& the battery is charged / discharged to store / discharge energy.

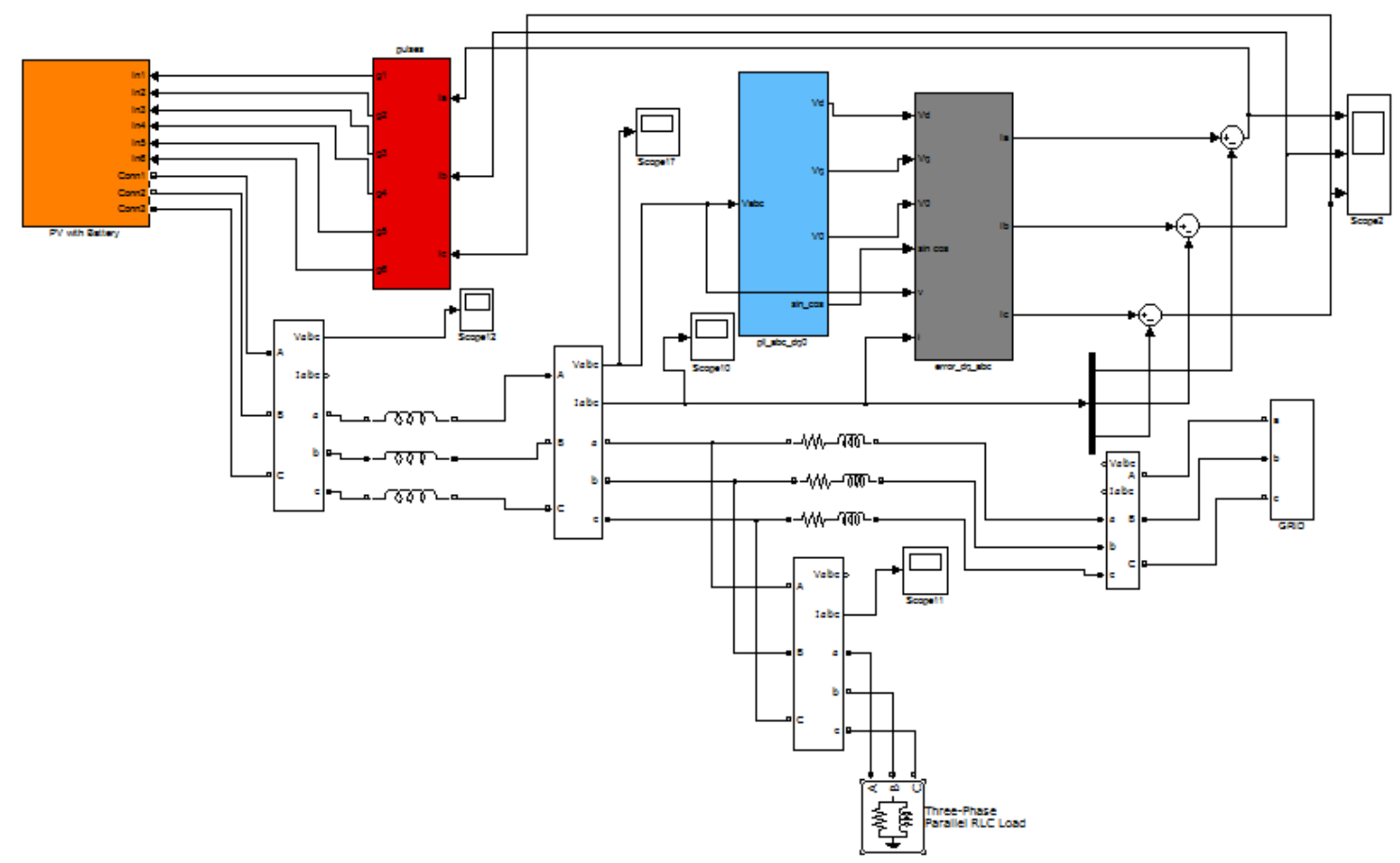

Fig 7. Simulation model of hybrid generation system

The output waveform obtained from simulation model as illustrated in fig 8 (a), (b), (c), (d), (e) and (f). 


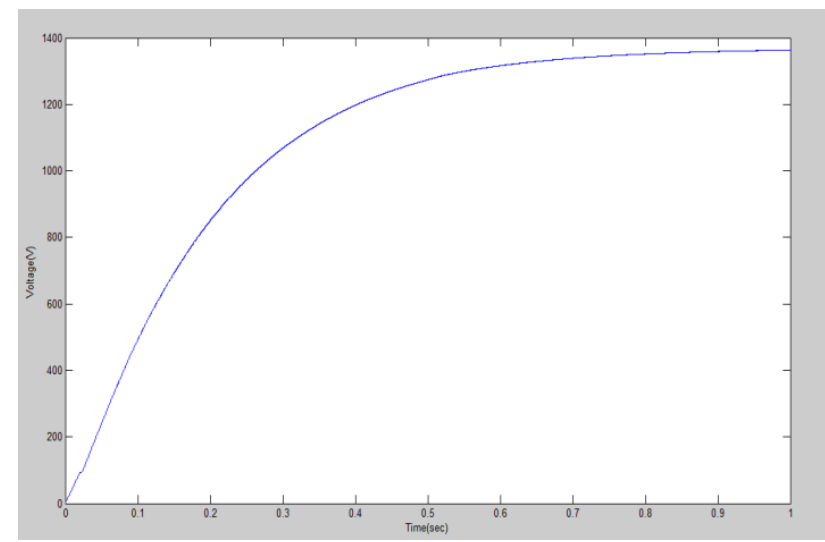

Figure 8 (a) Output Voltage of PV array

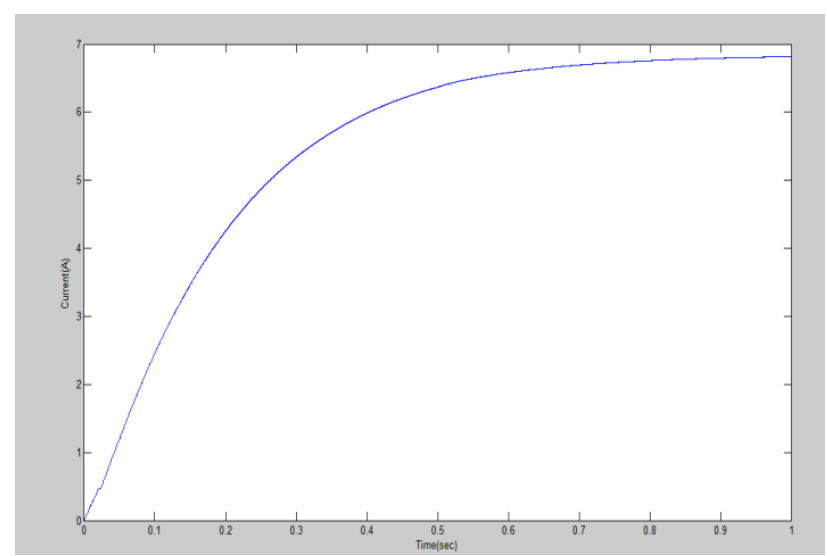

Figure 8 (b) Output Current of PV array

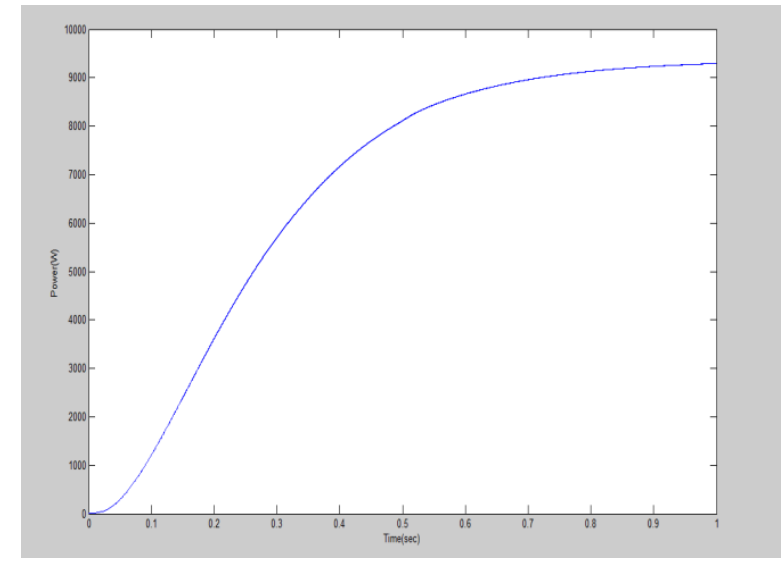

Figure 8 (c) Output Power of PV array

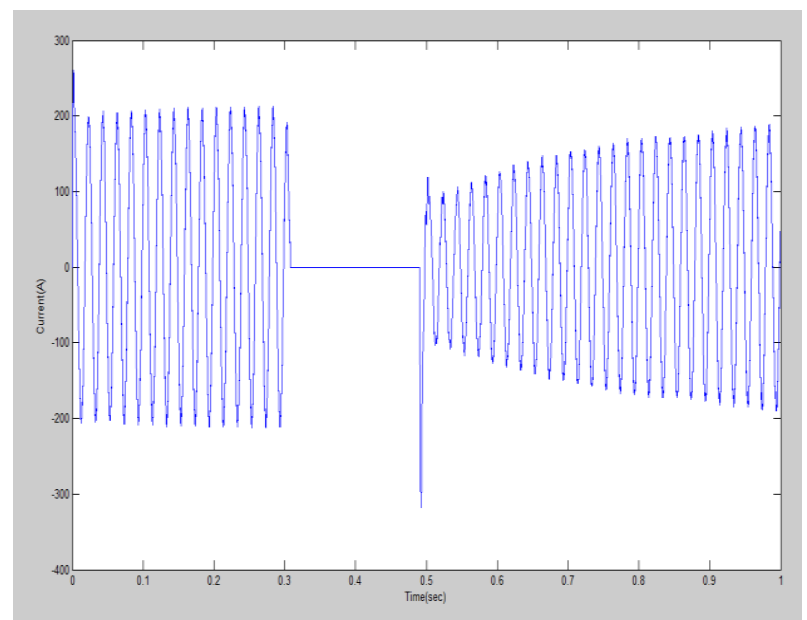

Figure 8 (d) Grid Current

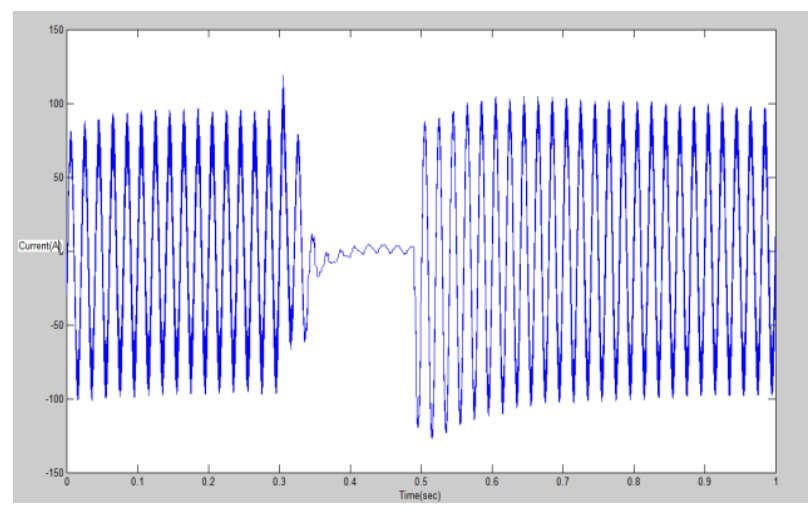

Figure 8 (e) Load Current

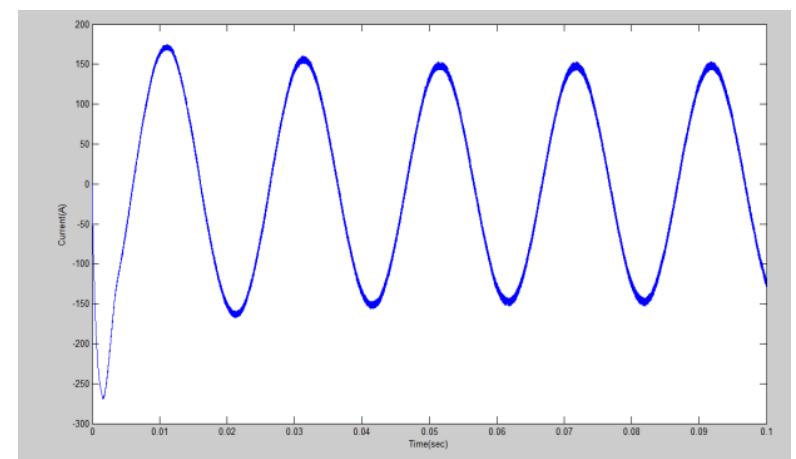

Figure 8 (f) Inverter Current

\section{CONCLUSION}

This paper studies about on grid PV / battery system for power generation. To utilize solar energy efficiently, it tracks maximum power point of PV module and generates most power with grid. The "P \& O method" can change the perturbation as the actual operating point changes. According to result, both tracking speed and algorithm accuracy are met. PV production changes as solar irradiance or temperature fluctuates. The charging and discharging of battery is performed to maintain a power balance between $\mathrm{PV}$ power generation and demand, improving overall system stability.

\section{REFERENCES}

1. MummadiVeerachary, "Control of TI-SEPIC Converter for Optimal Utilization of PV Power", IICPE, 2010 New Delhi.

2. M. Berrera, A. Dolara, R. Faranda and S. Leva, "Experimental test of seven widely-adopted MPPT algorithms", 2009 IEEE Bucharest Power Tech Conference, June 28th - July 2nd, Bucharest, Romania.

3. C.Hua and CShen, "Study of Maximum Power Tracking Technique and control of DC/DC CONVERTER FOR Photovoltaic system,",IEEE Computer soc.press,NewYork,USA, 1998

4. TrishanEsram. Patrick L, Chapman, "Comparison of Photovoltaic Array Maximum Power Point Tracking Techniques", IEEE Transaction on Energy Conversion, Vol 22, No.2, pp. 439-499, 2007.

5. Jingang Han, Tianhao Tang, Yao Xu, et at, "Design of storage system for a hybrid renewable power system", 2009 2nd Conference on Power Electronics and Intelligent Transportation System, Vol 2, pp. 67-70, 2009 